\title{
The impact of a community driven mass media campaign on the utilisation of maternal health care services in rural Malawi
}

\author{
Collins O. F. Zamawe ${ }^{1,2^{*}}$, Masford Banda ${ }^{3}$ and Albert N. Dube
}

\begin{abstract}
Background: Mass media is critical in disseminating public health information, improving health knowledge and changing health behaviours. However, most of the mass media public health interventions do not sufficiently engage the local people; they are externally determined. Due to this, very little is known about the effects of locally instigated mass media promotion. Therefore, the aim of this study was to examine the impact of a community driven mass media campaign called Phukusi la Moyo (tips of life) on the utilisation of maternal health care services.

Methods: A community-based cross-sectional study involving 3825 women of reproductive age (15-49 years) was conducted in rural Malawi to evaluate the Phukusi la Moyo (PLM) campaign. To do this, we compared the utilisation of maternal health care services between women who were exposed to the PLM campaign and those who were not. Respondents were identified using a multistage cluster sampling method. This involved systematically selecting communities (clusters), households and respondents. Associations were examined using Pearson chi square test and a multivariable logistic regression model.

Results: The likelihood of using contraceptives ( $A O R=1.61 ; 95 \% \mathrm{Cl}=1.32-1.96)$, sleeping under mosquito bed-nets $(A O R=1.65 ; 95 \% \mathrm{Cl}=1.39-1.97)$, utilising antenatal care services ( $A O R=2.62 ; 95 \% \mathrm{Cl}=1.45-4.73)$ and utilising postnatal care services ( $A O R=1.59 ; \mathrm{Cl}=1.29-1.95$ ) were significantly higher among women who had exposure to the PLM campaign than those who did not. No significant association was found between health facility delivery and exposure to the PLM campaign.

Conclusion: Women exposed to a community driven mass media campaign in rural Malawi were more likely to utilise maternal health care services than their unexposed counterparts. Since, the use of maternal health care services reduces the risk of maternal morbidity and mortality, community-led mass media could play a significant role towards improving maternal health outcomes in low-and-middle-income countries. Therefore, we recommend the use of locally driven mass media in disseminating public health information in limited resource settings.
\end{abstract}

Keywords: Women's health, Community intervention, Radio campaign, Phukusi la Moyo

\footnotetext{
* Correspondence: fzamawe@gmail.com

${ }^{1}$ Parent and Child Health Initiative (PACHI), Research Centre, Amina house,

Off Chilambula Road, P.O. Box 31686, Capital City, Lilongwe 3, Malawi

${ }^{2}$ The Ministry of Health, Lilongwe, Malawi

Full list of author information is available at the end of the article
} 


\section{Background}

Many people needlessly die every day due to lack of access to health information which would have allowed them or health workers to make appropriate decisions [1]. Thus, access to reliable health information is a cornerstone of improved and sustainable health outcomes [2]. In low-and-middle-income countries (LMIC), poor access to health information, especially among rural women is a major public health problem [3, 4]. It undermines efforts to bring health care services closer to the people. Hence, innovative strategies are required to meet the goal of 'Health Information For All' (HIFA) campaign [1].

Mass media is one of the popular and cost-effective public health promotion tools globally $[2,5,6]$. It is the main source of health information in many parts of the world, especially in LMIC. In Nigeria, for example, mass media is one of the major sources of information about malaria [7], women's health, HIV/AIDS and family planning among others [3]. Likewise, access to information in rural Tanzania is mainly through mass media (radio, television, newspapers), cell-phones and face to face communication [5]. Moreover, mass media interventions have been at the centre of maternal health and HIV prevention in Malawi $[4,8]$.

A growing body of evidence shows that mass media impacts public health knowledge, attitudes, beliefs and behaviours [9-11]. In Zambia, for example, exposure to radio and television programs about condom and HIV/ AIDS was associated with higher condom use [12]. Similarly, a behaviour change communication media campaign in Uganda improved knowledge of six months as the ideal period for exclusive breastfeeding [13]. In addition, media exposure significantly improved dietary diversity and meal frequency among infants and children in Ethiopia [14]. Further, a host of HIV media campaigns implemented between 1998 and 2007 in 23 countries effectively stimulated behaviour change [15].

In particular, the effects of mass media on maternal health behaviours have long been recognised in LMIC, where most of the maternal deaths occur $[6,16,17]$. In Nepal, exposure to mass media increased utilization of antenatal care services among rural women [18]. Comparable observations were made in Ghana, where exposure to mass media was recognized as a significant predictor of the likelihood that a woman would utilize antenatal care services and opt for childbirth assisted by a skilled provider [19]. Moreover, mass media impact men's involvement in maternal health. For example, Malawian women exposed to a specific media campaign reported higher participation of men in antenatal, postnatal and delivery care services [20].

Evidently, mass media is critical in disseminating public health information, improving health knowledge and changing health behaviours. Nonetheless, mass media campaigns have had inconsistent outcomes [3, 21]. A review of media campaigns on contraceptive use in LMIC demonstrated that most of the interventions had short-term effects, to the extent that demand for contraceptives would fall back to the initial level [22]. At country level, radio communication campaigns in Malawi had limited effect on condom use [4]. Likewise, media campaigns in Bangladesh appear to have no impact on contraceptive use [23].

Unreliable outcomes of mass media interventions in public health could be down to three factors: (a) media messages do not address cultural and practical barriers to behaviour change, (b) use of inappropriate media platforms to reach rural target audiences and (c) programs focus on one issue in the face of other related problems [24]. In short, most of the mass media interventions do not sufficiently engage the local people or community members $[6,25]$. Usually, what is branded as 'communitybased mass media' merely specifies that the "unit of intervention is at the community level" $[3,6,7,18]$. To be truly community grounded, an intervention is supposed to be developed and spearheaded by and for the communities it aims to serve [6]. Such interventions are more likely to be acceptable, sustainable and cost-effective [26-28].

Lack of community involvement implies that most of the public health mass media interventions are externally determined $[6,29,30]$. Owing to this, very little is known about the effects of locally instigated mass media promotion. For this reason, the aim of this study was to examine the impact of a mass media campaign (Phukusi la Moyo), which was initiated and led by the community members, on the utilisation of maternal health care services. The study will provide critical insights into the role of the community members in public health mass media interventions. This would help to inform and strengthen designs of future media interventions in maternal health and other global health areas.

\section{Methods}

\section{A synopsis of the Phukusi la Moyo campaign}

The Malawi Ministry of Health in collaboration with the Institute for Global Health (University College London) established a project called MaiMwana (mother and child) in 2003. The aim of the project was "to build capacities of communities in rural Malawi to take control of mother and child health issues that affect them" [31, 32]. The project was set up in Mchinji district, which was divided into 48 clusters. Of these, 24 received the women's group intervention [31]. Women in treatment clusters formed 207 groups to facilitate learning, sharing of lessons and to provide a platform for dealing with maternal health problems locally. The intervention was divided into four phases, with each having its main objective as follows: (a) to identify priority problems affecting women during 
pregnancy, delivery and postpartum; (b) to plan for the solutions of the problems identified and prioritised; (c) to implement the locally driven solutions to the problems and (d) to evaluate the solutions [31].

One of the major priority problems that most of the groups identified during phase one of the project was that health information was not accessible in some parts of the district due to shortage of community health workers. As a result, during phase two, the groups identified the feasibility of using a community radio to bring knowledge about maternal and child health issues to a large population. The groups agreed to lobby for a maternal health education program to be aired on the district's community radio station called "Mudziwanthu" (our community). Following that, a weekly radio program called "Phukusi la Moyo" (tips of life) was born. The intervention was implemented between 2009 and 2011.

As a radio campaign, the focus of Phukusi la Moyo (PLM) was to provide comprehensive maternal health information to women of reproductive age (15-49 years). The ultimate goal of the PLM campaign was to help reduce maternal and child mortality through improving utilisation of maternal health care services [31, 32]. The PLM's emphasis was on raising awareness of the risks associated with pregnancy, the importance of antenatal and postnatal care, and the advantages of delivering at the health facility. The campaign also aimed to promote (a) men's engagement in maternal health, (b) the use of mosquito bed-nets and (c) uptake of malaria prophylaxis among pregnant women.

The PLM campaign messages were delivered by means of different activities. These included panel discussions, community discussions, drama and songs. Members of the women's groups developed the radio programs with the technical support of the MaiMwana project and the Mudziwanthu radio station. The communities formed radio listening clubs, where women could listen to the program in groups and discuss the key messages afterwards.

\section{The study design}

A community-based cross-sectional study was conducted to evaluate the PLM interventions. This involved comparing the utilisation of maternal health care services between women who were exposed to the PLM campaign and those who were not. In the absence of the baseline data, this design was considered appropriate for the evaluation.

\section{The study setting}

The study was implemented in Mchinji, one of the 28 districts in Malawi. It is a typical rural district located in the central region of Malawi. Mchinji was particularly chosen because it was the catchment area of the PLM campaign, which this study intended to evaluate. The MaiMwana project divided the district into 48 equal clusters based on population size. This study was conducted in 24 of these 48 clusters, which were selected using a simple random sampling method.

\section{Population of the study and sample size}

Women of reproductive age (15-49 years) who gave birth or fell pregnant at least 12 months after the implementation of the PLM campaign were the target population of this study. The study engaged women only because the objective was to examine the utilisation of maternal health care services. Other inclusion criteria included: stayed continuously in the community between 2009 and 2013, willingness to participate and ability to provide informed consent. To allow meaningful analysis at cluster-level, the study included statistically reasonable number of respondents from each cluster. This was computed using G*Power version 3.1 program [33]. The minimum cluster sample size was 143 (effect size = 0.3 ; power $=0.80$; alpha $<0.05)$. Overall, data were collected from 3825 women.

\section{Data collection and sampling methods}

The data collection period was from July to December 2013. A team of 14 local research assistants conducted the fieldwork. They received a short training in research ethics and data collection. Data were collected using pretested structured electronic questionnaires, which were put in the Personal Digital Assistants (PDAs). Among other things, the questionnaire captured demographic details, exposure to the PLM program and utilisation of maternal health care services during the last pregnancy.

Respondents were systematically identified through a multistage cluster sampling method. In the first stage, the clusters were chosen using a simple random sampling technique. This was followed by selection of households through a systematic sampling approach. The sampling frame for each cluster was 160 . Finally, a single respondent was identified from each household using a simple random sampling method. The study registered $100 \%$ response rate.

\section{Description of study variables}

Five outcome variables were examined in this study. These were (a) utilisation of antenatal care services, (b) use of mosquito bed nets during pregnancy, (c) delivery at the health facility, (d) utilisation of postnatal care services and (e) use of contraceptives. All outcome variables were dichotomous (yes/no). Exposure to the PLM campaign was the main independent variable of this study. Respondents were either exposed or not (no/yes). The following covariates were also measured: highest education level, occupation, marital status and participation in the women's group intervention. 


\section{Data analysis}

The level of missing values in all relevant variables was below $5 \%$. As a result, all cases with missing values were discarded $(n=386)$ [34]. The final sample size of the study was 3439. Stata (version 12) was used for analysis. Descriptive statistics were used to describe variables. Then, we examined the relationships between independent and outcome variables using the Pearson chi-square $\left(x^{2}\right)$ test of independence. Finally, a multivariable logistic regression model was fitted to determine the direction and degree of the associations between the independent and outcome variables. Each outcome variable was examined twice against the independent variable: first, without adjusting for covariates and then, after controlling for marital status, age, occupation, participation in women's groups and education level. The relationships were estimated using crude and adjusted odds ratios and a $95 \%$ confidence interval. We used alpha $(\alpha)$ of $p<0.05$ to determine statistical significance.

\section{Ethical clearance and consent}

The protocol of this study was reviewed and approved by Malawi's National Health Sciences Research Committee (NHSRC). Participation in this study was voluntary and written informed consent was obtained from all the participants. Data collectors explained relevant details of the study to each potential respondent and asked if she would be interested in participating. Participants were required to sign or thumb-stamp the consent form. For participants under 18 years old (minors), additional written consent was obtained from their parents or guardians.

\section{Results}

\section{Characteristics of the participants}

Table 1 presents descriptive and bivariate results. Overall, the study engaged 3439 women residing in Mchinji district. The largest subgroup of the respondents were young women aged between 20 and 29 (47\%) followed by those between 30 and 39 years old (34\%). Very few teenage girls (7\%) and older women over the age of 40 (12\%) were involved. Most of the respondents at least attended primary education (72 \%), but none had gone beyond secondary school. A small number of participants (15\%) had no formal education. Most of the participants (74\%) were subsistent farmers. Regarding marital status, most of the respondents were married (90\%). Additionally, many participants were members of the women's groups (68\%).

\section{Sources of maternal health information and use of maternal health services}

Different sources of maternal health information were reported by our respondents. Most of them mentioned antenatal clinics followed by community health workers and radio (Fig. 1). Moreover, most participants (70 \%) acknowledged that they had access to the radio. In particular, around $60 \%$ of the participants were exposed to the PLM campaign (Table 1). We also assessed utilisation of maternal health care services. Women were asked about utilisation of maternal health care services during their last pregnancy. Almost all the women (98.4) attended antenatal care clinics, even though it was not certain if they fulfilled the recommended minimum of four visits. Similarly, most of the participants used contraceptives, delivered at the health facility, used postnatal care, and were sleeping under mosquito bed-net during pregnancy.

\section{Impact of the PLM campaign}

We examined the association between exposure to the PLM campaign and the utilisation of maternal health care services. The results indicate that there was a significant association between exposure to the PLM campaign and use of contraceptives $(p \leq 0.001)$, utilisation of antenatal care $(p \leq 0.001)$, sleeping under mosquito bed-nets $(p \leq 0.001)$ as well as utilisation of postnatal care $(p \leq 0.001)$. No significant association was found between exposure to the PLM program and delivery at the health facility $(p=0.209)$.

The results further show that the likelihood of using contraceptives $(\mathrm{OR}=1.72$; $95 \% \mathrm{CI}=1.43-2.07)$, mosquito bed-nets $(\mathrm{OR}=1.88 ; 95 \% \mathrm{CI}=1.59-2.22)$, antenatal care services $(\mathrm{OR}=2.90 ; 95 \% \mathrm{CI}=1.65-5.10)$, and postnatal care services $(\mathrm{OR}=1.64 ; \mathrm{CI}=1.35-1.99)$ were significantly higher among women who had exposure to the PLM campaign than those who did not. After adjusting for potential confounders (i.e. age, education, occupation, marital status, participation women's groups), women who had exposure to the PLM campaign were still significantly more likely to use contraceptives $(\mathrm{AOR}=1.61 ; 95 \%$ $\mathrm{CI}=1.32-1.96)$, mosquito bed-nets $(\mathrm{AOR}=1.65 ; 95 \%$ $\mathrm{CI}=1.39-1.97)$, antenatal care services $(\mathrm{AOR}=2.62 ; 95 \%$ $\mathrm{CI}=1.45-4.73$ ), and postnatal care services $(\mathrm{AOR}=1.59$; $\mathrm{CI}=1.29-1.95)$ than those who were not exposed; although with some reductions (Table 2). No significant association was found between health facility delivery and exposure to the PLM campaign.

\section{Discussion}

A community driven mass media campaign in rural Malawi was associated with improved utilisation of maternal health care services among women who were exposed to it. Specifically, exposure to the PLM campaign increased the likelihood of using contraceptives by $61 \%$, utilising antenatal care services by $162 \%$, sleeping under mosquito bed nets during pregnancy by $65 \%$ and utilising postnatal care by $59 \%$. This suggests that community driven mass media interventions are effective 
Table 1 Characteristics of the participants and bivariate results $(n=3439)$

\begin{tabular}{|c|c|c|c|c|c|c|c|}
\hline \multirow{3}{*}{$\begin{array}{l}\text { Variable } \\
\text { Total }\end{array}$} & \multirow{2}{*}{\multicolumn{2}{|c|}{ n (\%) }} & \multicolumn{4}{|c|}{ Exposure to PLM program } & \multirow[t]{3}{*}{$p$-value } \\
\hline & & & \multicolumn{2}{|l|}{ No (\%) } & \multicolumn{2}{|c|}{ Yes (\%) } & \\
\hline & 3439 & $(100.0)$ & 1349 & $(39.2)$ & 2090 & $(60.8)$ & \\
\hline \multicolumn{8}{|l|}{ Age (years) } \\
\hline $15-19$ & 224 & $(6.5)$ & 102 & $(45.5)$ & 122 & $(54.5)$ & \multirow[t]{4}{*}{$<0.003^{*}$} \\
\hline $20-29$ & 1628 & $(47.3)$ & 590 & $(36.2)$ & 1038 & $(63.8)$ & \\
\hline $30-39$ & 1183 & $(34.4)$ & 480 & (40.6) & 703 & $(59.4)$ & \\
\hline $40-49$ & 404 & $(11.8)$ & 177 & $(43.8)$ & 227 & $(56.2)$ & \\
\hline \multicolumn{8}{|l|}{ Education } \\
\hline None & 529 & $(15.4)$ & 261 & $(49.3)$ & 268 & $(50.7)$ & \multirow[t]{3}{*}{$<0.001^{*}$} \\
\hline Primary school & 2463 & $(71.6)$ & 964 & (39.1) & 1499 & $(60.9)$ & \\
\hline Secondary school & 447 & $(13.0)$ & 124 & $(27.7)$ & 323 & $(72.3)$ & \\
\hline \multicolumn{8}{|l|}{ Marital status } \\
\hline Never married & 99 & $(2.9)$ & 53 & (53.5) & 46 & $(46.5)$ & \multirow[t]{3}{*}{$<0.001^{*}$} \\
\hline Currently married & 3094 & $(90.0)$ & 1180 & $(38.1)$ & 1,914 & $(61.9)$ & \\
\hline Formerly married & 246 & $(7.2)$ & 116 & $(47.1)$ & 130 & $(52.9)$ & \\
\hline \multicolumn{8}{|l|}{ Occupation } \\
\hline Farmers & 2559 & $(74.4)$ & 1033 & $(40.4)$ & 1526 & $(59.6)$ & \multirow[t]{4}{*}{$<0.001^{*}$} \\
\hline Self employed & 514 & $(15.0)$ & 159 & (30.9) & 355 & $(69.1)$ & \\
\hline Casual worker & 273 & (7.9) & 119 & (43.6) & 154 & $(56.4)$ & \\
\hline Others & 93 & $(2.7)$ & 38 & $(40.9)$ & 55 & $(59.1)$ & \\
\hline \multicolumn{8}{|c|}{ Women's group member } \\
\hline No & 2341 & $(68.1)$ & 1090 & (46.6) & 1251 & $(53.4)$ & \multirow[t]{2}{*}{$<0.001^{*}$} \\
\hline Yes & 1098 & $(31.9)$ & 259 & (23.6) & 839 & $(76.4)$ & \\
\hline \multicolumn{8}{|l|}{ Used contraceptives } \\
\hline No & 529 & $(15.4)$ & 267 & $(50.5)$ & 262 & $(49.5)$ & \multirow[t]{2}{*}{$<0.001^{*}$} \\
\hline Yes & 2910 & $(84.6)$ & 1082 & $(37.2)$ & 1828 & $(62.8)$ & \\
\hline \multicolumn{8}{|c|}{ Utilised antenatal health care services } \\
\hline No & 54 & $(1.6)$ & 35 & $(64.8)$ & 19 & $(35.2)$ & \multirow[t]{2}{*}{$<0.001^{*}$} \\
\hline Yes & 3385 & $(98.4)$ & 1314 & (38.8) & 2071 & $(61.2)$ & \\
\hline \multicolumn{8}{|c|}{ Sleeping under bed-nets during pregnancy } \\
\hline No & 710 & $(20.6)$ & 365 & (51.4) & 345 & $(48.6)$ & \multirow[t]{2}{*}{$<0.001^{*}$} \\
\hline Yes & 2729 & $(79.4)$ & 984 & $(36.1)$ & 1745 & $(63.9)$ & \\
\hline \multicolumn{8}{|c|}{ Delivered at health facility } \\
\hline No & 271 & $(7.9)$ & 116 & $(42.8)$ & 155 & $(57.2)$ & \multirow[t]{2}{*}{$0.209^{* *}$} \\
\hline Yes & 3168 & $(92.1)$ & 1233 & $(38.9)$ & 1935 & $(61.1)$ & \\
\hline \multicolumn{8}{|c|}{ Utilised postnatal health care services } \\
\hline No & 469 & $(13.6)$ & 233 & $(49.7)$ & 236 & $(50.3)$ & \multirow[t]{2}{*}{$<0.001^{*}$} \\
\hline Yes & 2970 & $(86.4)$ & 1116 & (37.6) & 1854 & $(62.4)$ & \\
\hline
\end{tabular}

PLM phukusi la moyo

*Significant $(p<0.05)$; **Not significant $(p>0.05)$

in improving uptake of maternal health care services in limited resource settings.

The main focus of PLM was to raise awareness of the maternal health complications and the importance of family planning, antenatal care, postnatal care and delivering at the health facility. Therefore, increased utilisation of maternal health care services among women exposed to the PLM campaign was likely due to improved knowledge of maternal health issues. This is consistent with other studies in LMIC that have shown that mass 


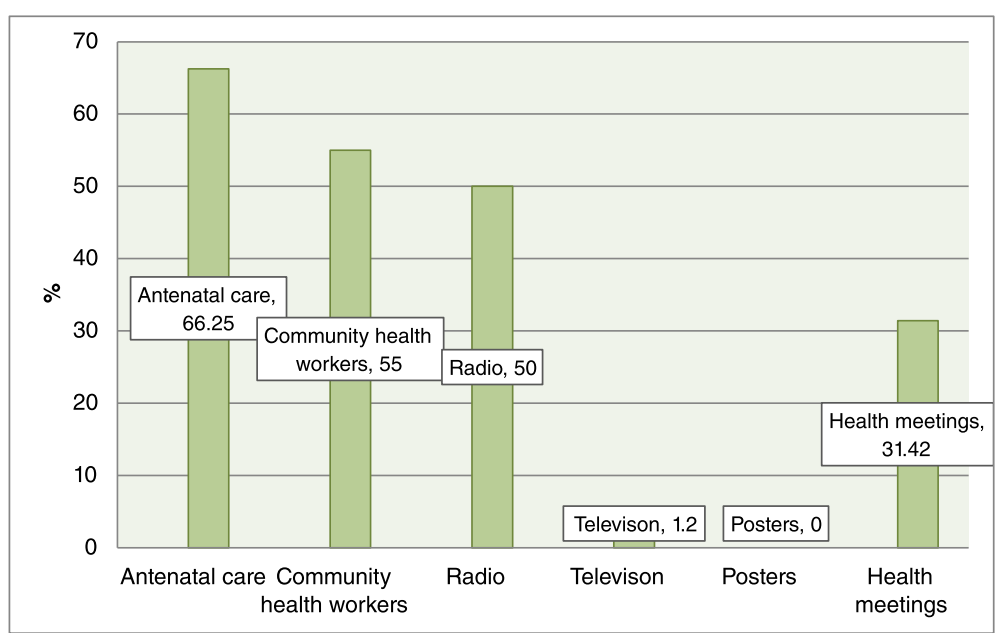

Fig. 1 Sources of maternal health information (multiple responses)

media campaigns influence knowledge and behaviours $[35,36]$. However, most of the earlier mass media promotions were externally developed with no input from the targeted communities $[6,8,18]$. The PLM campaign was different; it employed a bottom-up approach. Therefore, the results of this study add a new dimension to the literature of mass media in global health.

Moreover, our outcomes demonstrate that a true community centred approach is conceivable in mass media.
Like other health programs, we believe that the benefits of mass media would be maximised if the campaigns are grounded in the targeted communities. For instance, apart from the intended outcomes, community involvement in public health mass media interventions would probably promote self-reliance/ownership, encourage the use of locally available resources and address priority health needs $[37,38]$. To this effect, where appropriate, a bottom-up approach should be prioritised in media interventions

Table 2 Exposure to the PLM campaign and the utilisation of maternal health care services (logistic model) $(n=3439)$

\begin{tabular}{|c|c|c|c|c|c|c|}
\hline Outcome variables & OR & $(95 \% \mathrm{Cl})$ & $p$-value & $\mathrm{AOR}$ & $(95 \% \mathrm{Cl})$ & $p$-value \\
\hline \multicolumn{7}{|l|}{ Used contraceptives } \\
\hline No (Rc) & 1.00 & & & & & \\
\hline Yes & 1.72 & $(1.43-2.07)$ & $<0.001^{*}$ & 1.61 & $(1.32-1.96)$ & $<0.001^{*}$ \\
\hline \multicolumn{7}{|c|}{ Utilised antenatal care services } \\
\hline No (Rc) & 1.00 & & & & & \\
\hline Yes & 2.90 & $(1.65-5.10)$ & $<0.001^{*}$ & 2.62 & $(1.45-4.73)$ & 0.001 \\
\hline \multicolumn{7}{|l|}{ Slept under bed-net } \\
\hline No (Rc) & 1.00 & & & & & \\
\hline Yes & 1.88 & $(1.59-2.22)$ & $<0.001^{*}$ & 1.65 & $(1.39-1.97)$ & $<0.001^{*}$ \\
\hline \multicolumn{7}{|c|}{ Delivered at a health facility } \\
\hline No (Rc) & 1.00 & & & & & \\
\hline Yes & 1.17 & $(0.91-1.51)$ & $0.209^{* *}$ & 1.11 & $(0.85-145)$ & $0.44^{* *}$ \\
\hline \multicolumn{7}{|c|}{ Utilised postnatal care services } \\
\hline No (Rc) & 1.00 & & & & & \\
\hline Yes & 1.64 & $(1.35-1.99)$ & $<0.001^{*}$ & 1.59 & $(1.29-1.95)$ & $<0.001^{*}$ \\
\hline
\end{tabular}

$O R$ Odds ratio

AOR Adjusted odds ratio

$\mathrm{Cl}$ Confidence interval

$R c$ Reference category

*Significant $(p<0.05)$

**Not significant $(p>0.05)$ 
targeting the rural masses. In the meantime, however, there is a need to compare the impact of the community driven and externally determined media interventions.

In particular, community driven media campaigns could be critical in improving maternal health outcomes in LMIC. Although the utilisation of maternal health care services reduces the risk of maternal morbidity and mortality, some of the women continue to shun these health care services [17, 39, 40]. The findings of this research reveal that locally driven mass media could be a reliable instrument for enhancing uptake of maternal health care services.

The findings of this study further indicate that mass media is or could be an essential platform for transmitting health information in rural areas. Over $70 \%$ of the participants had access to the radio and about $50 \%$ of the women also indicated that the radio was the main source of maternal health information. Similar findings have also been observed elsewhere [3, 5, 41]. Since the shortage of community health workers makes it impossible to reach every woman (especially in rural areas) with maternal health information [42], community driven mass media campaigns could be a reliable alternative.

While recommending community driven mass media campaigns, we would like to recognise the need for the community members to adequately engage professional health care workers in the production of campaign materials. This would ensure that correct information is made available. Besides, more community radio stations should be set up in rural places. This would allow broadcasting of tailor-made programs like the PLM that meet the specific needs of the people in a particular setting. Equally, it is logical to expand the signal radius of the existing community radio stations to reach out to more people living in the remote areas.

This study had some limitations and strengths. Due to the cross-sectional design, we could not establish causaleffect relationships. Besides, owing to the self-reporting of both exposure and health behaviours, we cannot rule out the recall and social desirability biases. Nonetheless, the statistical significance was robust due to relatively large sample size.

\section{Conclusion}

Women exposed to a community driven mass media campaign in rural Malawi were significantly more likely to utilise maternal health care services than their unexposed counterparts. Since, the use of maternal health care services reduces the risk of maternal morbidity and mortality, community driven mass media could play a significant role towards improving maternal health outcomes in LMIC. To this end, community driven mass media interventions should be promoted, especially in limited resource settings.

\section{Abbreviations}

AOR: adjusted odds ratio; Cl: confidence interval; LMIC: low-and-middleincome-countries; NHSRC: National Health Sciences Research Committee; PDA: Personal Digital Assistants; PLM: Phukusi la Moyo.

\section{Competing interests}

The authors declare that they have no competing interests.

\section{Authors' contributions}

CZ designed the study, contributed to the fieldwork, performed statistical analysis and drafted the manuscript. MB designed the study, contributed to the fieldwork and performed statistical analysis. AD designed the study, contributed to the fieldwork, performed statistical analysis. All the authors read and approved the final manuscript.

\section{Acknowledgements}

We would like to recognise the support, which we received from all the members of the Phukusi la Moyo steering committee. We also acknowledge the contribution of Fatsani Kusamula, Mark Manyau, Tambosi Phiri, Bright Singini and Florida Malamba during data collection. The Commonwealth of Learning (CoL) funded both Phukusi la Moyo radio program and the current study. However, the funder played no part in the designing of this study and did not influence our decision to publish these results.

We are also grateful to Masautso Chimombo (Lilongwe University of Agriculture and Natural Resources), Neo Kazembe (Dignitas International) and Aggie Wizi (Catholic University of Malawi) for editing our draft manuscript.

\section{Author details}

${ }^{1}$ Parent and Child Health Initiative (PACHI), Research Centre, Amina house, Off Chilambula Road, P.O. Box 31686, Capital City, Lilongwe 3, Malawi. ${ }^{2}$ The Ministry of Health, Lilongwe, Malawi. ${ }^{3}$ MaiMwana Project, P.O. Box 2, Mchinji, Malawi. ${ }^{4}$ The University of Malawi, College of Medicine, School of Public Health, Blantyre, Malawi.

Received: 4 June 2015 Accepted: 25 January 2016

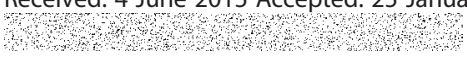

\section{References}

1. A global campaign: healthcare information for all by 2015 [http://www. hifa2015.org/about/why-hifa2015-is-needed/]. Accessed date 2 Jun 2015

2. Godlee F, Pakenham-Walsh N, Ncayiyana D, Cohen B, Packer A. Can we achieve health information for all by 2015? Lancet. 2004;364:295-300.

3. Nwagwu WE, Ajama M. Women 's health information needs and information sources: a study of a rural oil palm business community in South-Western Nigeria. Ann Libr Inf Stud. 2011;58:270-81.

4. Meekers D, Van Rossem R, Silva M, Koleros A. The reach and effect of radio communication campaigns on condom use in Malawi. Stud Fam Plann. 2007:38:113-20.

5. Mtega WP. Access to and Usage of Information among Rural Communities: a Case Study of Kilosa District Morogoro Region in Tanzania. Can J Libr Inf Pract Res. 2013;7:1-9.

6. Sood S, Shefner-Rogers C, Skinner J. Health Communication Campaigns in Developing Countries. J Creat Commun. 2014;9:67-84.

7. Umeano-Enemuoh JC, Uzochukwu B, Ezumah N, Mangham-Jefferies L, Wiseman V, Onwujekwe O. A qualitative study on health workers' and community members' perceived sources, role of information and communication on malaria treatment, prevention and control in southeast Nigeria. BMC Infect Dis. 2015;15:437

8. Reijer P, Chalimba M, Nakwagala AA. Malawi goes to scale with anti-AIDS clubs and popular media. Eval Program Plann. 2002;25:357-63.

9. LaCroix JM, Snyder LB, Huedo-Medina TB, Johnson BT. Effectiveness of mass media interventions for HIV prevention, 1986-2013: a meta-analysis. J Acquir Immune Defic Syndr. 2014;66 Suppl 3:S329-40.

10. Naugle DA, Hornik RC. Systematic Review of the Effectiveness of Mass Media Interventions for Child Survival in Low- and Middle-Income Countries. J Health Commun. 2014;19:190-215.

11. Robinson MN, Tansil KA, Elder RW, Soler RE, Labre MP, Mercer SL, et al. Mass Media Health Communication Campaigns Combined with Health-Related Product Distribution. Am J Prev Med. 2014;47:360-71. 
12. Van Rossem R, Meekers D. The reach and impact of social marketing and reproductive health communication campaigns in Zambia. BMC Public Health. 2007;7:352

13. Gupta N, Katende C, Bessinger R. An evaluation of post-campaign knowledge and practices of exclusive breastfeeding in Uganda. J Health Popul Nutr. 2004:22:429-39.

14. Beyene M, Worku AG, Wassie MM. Dietary diversity, meal frequency and associated factors among infant and young children in Northwest Ethiopia: a cross- sectional study. BMC Public Health. 2015;15:1007.

15. Noar SM, Palmgreen P, Chabot M, Dobransky N, Zimmerman RS. A 10-year systematic review of HIV/AIDS mass communication campaigns: Have we made progress? J Health Commun. 2009;14:15-42.

16. Tsawe M, Moto A, Netshivhera T, Ralesego L, Nyathi C, Susuman AS. Factors influencing the use of maternal healthcare services and childhood immunization in Swaziland. Int J Equity Health. 2015;14:32.

17. United Nations. The Millennium Development Goals Report 2014. New York; 2014. http://www.who.int/woman_child_accountability/ierg/reports/2012 15S_MassMediaEvidenceBase.pdf. Accessed date 20 May 2015.

18. Acharya D, Khanal V, Singh JK, Adhikari M, Gautam S. Impact of mass media on the utilization of antenatal care services among women of rural community in Nepal. TT -. BMC Res Notes. 2015;8:4-9.

19. Asmah EE, Twerefou DK, Smith JE. Health Campaigns and Use of Reproductive Health Care Services by Women in Ghana. Am J Econ. 2013:3:243-51.

20. Zamawe C, Banda M, Dube A. The effect of mass media campaign on Men's participation in maternal health: a cross-sectional study in Malawi. Reprod Health. 2015;12:31.

21. Asp G, Pettersson KO, Sandberg J, Kabakyenga J, Agardh A. Associations between mass media exposure and birth preparedness among women in southwestern Uganda: A community-based survey. Glob Health Action. 2014;7:1-9.

22. Hornik R, McAnany E. Theories and Evidence: Mass Media Effects and Fertility Change. Commun Theory. 2001;11:454-71.

23. Raut MK. Interpersonal communication and contraception: Insights and evidences from Bangladesh demographic and health survey, 2011. Indian J Public Health. 2015;59:220-4.

24. Snell W. Mass Media: The Evidence Base. London; 2012. http://www.who.int/ woman_child_accountability/ierg/reports/2012_15S_ MassMediaEvidenceBase.pdf. Accessed date 19 Apr 2015.

25. Creel AH, Rimal RN, Mkandawire G, Böse K, Brown JW. Effects of a mass media intervention on HIV-related stigma: "Radio Diaries" program in Malawi. Health Educ Res. 2011;26:456-65.

26. Colbourn T, Nambiar B, Bondo A, Makwenda C, Tsetekani E, Makonda-Ridley $A$, et al. Effects of quality improvement in health facilities and community mobilization through women's groups on maternal, neonatal and perinatal mortality in three districts of Malawi: MaiKhanda, a cluster randomized controlled effectiveness trial. Int Health. 2013;5:180-95.

27. Manandhar DS, Osrin D, Shrestha BP, Mesko N, Morrison J, Tumbahangphe $\mathrm{KM}$, et al. Effect of a participatory intervention with women's groups on birth outcomes in Nepal: cluster-randomised controlled trial. Lancet. 2004;364:970-9.

28. More NS, Bapat U, Das S, Alcock G, Patil S, Porel M, et al. Community mobilization in Mumbai slums to improve perinatal care and outcomes: A cluster randomized controlled trial. PLoS Med. 2012;9.

29. Kane TT, Gueye M, Speizer I, Pacque-margolis S, Baron D. The Impact of a Family in Campaign Planning Bamako, Multimedia Mali. Stud Fam Plann. 1998;29:309-23.

30. Davis J, Luchters S, Holmes W. Men and Maternal and Newborn Health: Benefits, Harms, Challenges and Potential Strategies for Engaging Men. Melbourne; 2013. http://www.wchknowledgehub.com.au/sites/default/files/ BP_Davis_FEB13.pdf. Accessed date 30 May 2015.

31. Rosato M, Mwansambo C, Lewycka S, Kazembe P, Phiri T, Malamba F, et al. MaiMwana women's groups: A community mobilisation intervention to improve mother and child health and reduce mortality in rural Malawi. Malawi Med J. 2010;22:112-9

32. Lewycka S, Mwansambo C, Rosato M, Kazembe P, Phiri T, Mganga A, et al. Effect of women's groups and volunteer peer counselling on rates of mortality, morbidity, and health behaviours in mothers and children in rural Malawi (MaiMwana): A factorial, cluster-randomised controlled trial. Lancet. $2013 \cdot 381: 1721-35$
33. Faul F, Erdfelder E, Lang A-G, Buchner A. G*Power 3: a flexible statistical power analysis program for the social, behavioral, and biomedical sciences. Behav Res Methods. 2007;39:175-91.

34. Baraldi AN, Enders CK. An introduction to modern missing data analyses. J Sch Psychol. 2010;48:5-37.

35. Mashreky SR, Rahman F, Rahman A, Talab A, Rahman Z. Role of mass media in increasing knowledge and practices of mothers on IYCF: findings from a community trial in rural Bangladesh. South East Asia J Public Heal. 2015;5:18

36. Mishra SR, Adhikari S, Khanal V. Role of mass media on knowledge generation and countering misconceptions about tuberculosis transmission in Nepal. Asian Pac J Trop Biomed. 2014:4:S610-5.

37. Jimba M, Poudel-Tandukar K, Poudel KC. School and community health project: Part 1: A community development and health project in Nepal. Japan Med Assoc J. 2008;51:225-34.

38. Rosato M, Laverack G, Grabman LH, Tripathy P, Nair N, Mwansambo C, et al. Community participation: lessons for maternal, newborn, and child health. Lancet. 2008;372:962-71.

39. Ahmed S, Li Q, Liu L, Tsui AO. Maternal deaths averted by contraceptive use: An analysis of 172 countries. Lancet. 2012;380:111-25.

40. Yego F, D'Este C, Byles J, Williams JS, Nyongesa P. Risk factors for maternal mortality in a Tertiary Hospital in Kenya: a case control study. BMC Pregnancy Childbirth. 2014;14:38.

41. Bosompra K. Sources of Health Information Among Rural Dwellers in Africa: A Case Study of Two Ghanaian Villages. African media Rev. 1987;1:120-33.

42. Warren C. Care seeking for maternal health: challenges remain for poor women. Ethiop J Heal. 2010;24:100-4.

\section{Submit your next manuscript to BioMed Central and we will help you at every step:}

- We accept pre-submission inquiries

- Our selector tool helps you to find the most relevant journal

- We provide round the clock customer support

- Convenient online submission

- Thorough peer review

- Inclusion in PubMed and all major indexing services

- Maximum visibility for your research

Submit your manuscript at www.biomedcentral.com/submit

) Biomed Central 